\title{
ALTERAÇÕES TECNOGÊNICAS NA BACIA HIDROGRÁFICA DO ARROIO SAPUCAIA, MUNICÍPIO DE GRAVATAÍ (RS)
}

\author{
Technogenics changes in the hydrographic basin of Arroio Sapucaia, \\ municipality of Gravataí (RS)
}
Alteraciones tecnogenicas en la cuenca hidrográfica del Arroyo Sapucaia, municipio de Gravataí (RS)

\author{
Wagner Costa Cattaneo* \\ Nina Simone Vilaverde Moura** \\ * Universidade Federal do Rio Grande do Sul (UFRGS) \\ - wagnercostac2014@gmail.com \\ ** Universidade Federal do Rio Grande do Sul (UFRGS) \\ - nina.moura@ufrgs.br
}

Recebido em 10/03/2029. Aceito para publicação em 13/07/2021.

Versão online publicada em 09/08/2021 (http://seer.ufrgs.br/paraonde)

Como citar este artigo: WAGNER, C. C. MOURA, N. S. V. Alterações tecnogênicas na bacia hidrográfica do Arroio Sapucaia, município de Gravataí (RS). Para Onde!?, v. 15, n. 1, p. 96111, 2021.

Resumo:

A presente pesquisa tem 0 intuito de analisar os elementos naturais e os transformados ou induzidos pelos agentes sociais (ou ações antrópicas) de forma integrada na bacia hidrográfica do arroio Sapucaia (RS). A bacia hidrográfica do arroio Sapucaia possui extensão territorial de $129,7 \mathrm{~km}^{2}$ e abrange seis municípios da Região Metropolitana de Porto Alegre/RS. Na sub-bacia hidrográfica do arroio Santa Tecla, no município de Gravataí/RS, pode-se identificar a mais extensa cicatriz de mineração em áreas de nascentes com predomínio de atividades rurais (agropecuária). Observou-se que os empreendimentos mineradores contribuem como agente desencadeador de processos erosivos e assoreamento de canais e áreas úmidas (banhados). Os principais pressupostos teóricos-metodológico que orientaram o estudo referem-se a abordagem ambiental relacionada ao conceitos de depósitos tecnogênicos no sistema fluvial, conforme Chemekov (1983) e Oliveira (1990). Além disso, os procedimentos metodológico e técnicos para uma análise granulométrica dos depósitos tecnogênicos, com base na escala de Wentworth e a Lei de Stokes, foram fundamentais na caracterização granulométricas dos referidos depósitos. Por último, outra referência fundamental, foi o uso de ferramentas de sensoriamento remoto para o reconhecimento do terreno e identificação das classes de uso e ocupação da terra. Dessa forma, compreendeu-se que algumas classes de uso da terra exercem maior pressão sobre o ambiente no setor de nascentes, com desdobramentos na rede de drenagem. Pode-se constatar, através de análise sedimentológica e observações em trabalhos de campo, a influência da atividade mineradora na disponibilidade de sedimentos ao ambiente e seu reflexo no leito dos arroios, sobretudo na sub-bacia do arroio Santa Tecla, induzindo o assoreamento dos canais.

Palavras-chave: Bacia hidrográfica do arroio Sapucaia. Sub-bacia do arroio Santa Tecla. Uso e ocupação da terra. Depósitos tecnogênicos. 


\begin{abstract}
:
The present research is made up of an integrated analysis between naturals factors and factors induced or transformed for social agents. The hydrographic basin of the Sapucaia' stream has a territorial extension of $129.7 \mathrm{~km}^{2}$ and covers six municipalities in the Metropolitan Region of Porto Alegre / RS. In the hydrographic sub-basin Santa Tecla , in the municipality of Gravataí / RS, it is possible identifying the most extensive mining's scar, the area has a predominance of rural activities in terms of land usage and occupation, also it is an important area due many springs of the streams. It was observed, then, how the mining enterprises contribute as a driving force triggering erosive processes and silting of channels and wetlands. As methodological support, knowledge of the geological and geomorphological sciences was applied in their environmental approach according to the assumptions of Chemekov (1983) and Oliveira (1990) placing the technogenic deposits of fluvial origin concept, the use of granulometric analysis techniques based on the Wentworth scale and Stokes' Law, as also, it was used of remote sensing tools for recognition and for identification of land, defining usage and occupation classes. Thus, it was understood that some classes of land usage exert greater pressure on the environment in the springs sector, bringing consequences in the drainage network. It can be seen, through sedimentological analysis in a specialized laboratory, and also through observations at field work, there is influence of mining activity on the availability of sediment in the environment and it reflect at stream bed, especially in the hydrographic sub-basin Santa Tecla, causing the silting of the channels.
\end{abstract}

Key words: Hydrographic basin of the Sapucaia stream. Hydrographic sub-basin Santa Tecla. Land usage and occupation. Technogenic deposits.

\title{
Resumen:
}

Esta investigación consiste en un análisis integrador entre elementos naturales y aquellos transformados o inducidos por agentes sociales. La cuenca hidrográfica del arroyo Sapucaia tiene una extensión territorial de $129,7 \mathrm{~km}^{2}$ y cubre seis municipios de la Región Metropolitana de Porto Alegre / RS. En la subcuenca hidrográfica del arroyo Santa Tecla, en el municipio de Gravataí / RS, se identifica la cicatriz minera más extensa, un lugar con predominio de actividades rurales en términos de uso y ocupación del suelo, y una importante área de manantiales de arroyos. Se observó cómo las empresas mineras contribuyen como motor impulsor desencadenando procesos erosivos y sedimentación de canales y humedales. Como soporte metodológico se aplicó el conocimiento de las ciencias geológicas y geomorfológicas en su abordaje ambiental según los supuestos de Chemekov (1983) y Oliveira (1990) en la aplicación del concepto de yacimientos tecnogénicos de origen fluvial, el uso de técnicas de análisis granulométrico basado en la escala de Wentworth y la Ley de Stokes, así como el uso de herramientas de teledetección para el reconocimiento de tierras y la identificación de clases de ocupación y uso de la tierra. Así, se entendió que algunas clases de uso del suelo ejercen mayor presión sobre el medio ambiente en el sector de manantiales, con consecuencias en la red de drenaje. Se puede apreciar, mediante análisis sedimetológico en laboratorio especializado y observaciones en trabajo de campo, la influencia de la actividad minera sobre la disponibilidad de sedimentos en el ambiente y su reflejo en el cauce del arroyo, especialmente en la subcuenca del arroyo Santa Tecla, induciendo la sedimentación de los canales.

Palabras clave: Cuenca hidrográfica del arroyo Sapucaia. Subcuenca hidrográfica del arroyo Santa Tecla. Uso y ocupación del suelo. Depósitos tecnogénicos. 


\section{Introdução}

O presente artigo deriva da dissertação de mestrado que analisa as alterações antrópicas na bacia hidrográfica do arroio Sapucaia onde observou-se a importante ação do fator minerador em uma de suas sub-bacias em área de nascentes. Pensar o ambiente revela a relação/conexão entre o uso da natureza e a organização social que dela se apropria. Investigar o ambiente sob um panorama de relação natureza e sociedade revela o quão o homem está inserido e depende dos recursos naturais para o seu sustento, ao mesmo tempo em que cria novas condicionantes para as gerações futuras, ou seja, uma natureza transformada, um ambiente. A questão ambiental traz a discussão sobre a finitude dos recursos naturais, faz menção à técnica empregada que pode resultar em conservação, preservação ou degradação e, também, revela o modo de vida dos agentes sociais que deixam marcas em registros estratigráficos. Os traçados das relações humano-ambientais se materializam na paisagem, evidenciando desdobramentos horizontais no espaço, deixando, também, assinaturas verticais estratigráficas destas mudanças no tempo. Desta maneira, torna-se cada vez mais importante pensar o ambiente como resultado da articulação entre o natural e o social no tempo e espaço.

A unidade espacial escolhida para a pesquisa é a bacia hidrográfica por favorecer análise integradora entre o meio físico e o social, fundamentalmente por constituir um sistema natural bem delimitado geograficamente onde há constante troca de matéria e energia (CHRISTOFOLETTI, 1980). Os diferentes usos que o homem faz dentro dos limites da unidade de bacia têm respostas nas águas que a drenam, sejam superficiais ou subterrâneas, além dos reflexos nos demais elementos que compõem o sistema hidrológico como o relevo, o solo, o ar e a vegetação.

Materiais derivados do uso do solo podem ser transferidos para o sistema hidrológico após eventos seguidos de chuvas e formar depósitos sob planícies fluviais. Os registros físicos ocorrem em setores onde os cursos fluviais extravasam os canais e sedimentam produtos da ocupação da terra, originando testemunhos estratigráficos, de acordo com os pressupostos de Chemekov (1983) e Oliveira (1990). Os sedimentos transportados pelas águas em superfície e abandonados nas planícies contem assinaturas do que ocorre com o uso da terra numa bacia hidrográfica, principalmente atividades que utilizam grandes extensões territoriais e geram fluxos de materiais como exploração de recursos minerais, agropecuária e estabelecimento de moradias.

A presente pesquisa pode contribuir em despertar a atenção e provocar debate para o uso do solo em áreas próximas de nascentes e, no caso específico, numa área de enclave rural cercado pela grande urbe do Rio Grande do Sul. Através de análises da composição dos sedimentos foi possível identificar materiais residuais provenientes das atividades ligadas ao uso da terra, obtendo, assim, um diagnóstico das condições ambientais atuais e uma contribuição científica à reflexão sobre as tomadas de decisões futuras. 


\title{
2. Referencial Teórico e Metodológico
}

\section{a. O Ambiente nos estudos geográficos e a bacia hidrográfica}

Para Guerra e Cunha (2010), o conceito de ambiente (natural e social) tem passado por sucessivas transformações ao longo da história. $\mathrm{O}$ ambiente, em função dos interesses econômicos e políticos, vem passando por um processo de degradação acentuado no século XX, causando drástica diminuição da qualidade de vida e aumento da preocupação mundial em tentar reverter o quadro (GUERRA e CUNHA, 2010). A degradação ambiental é resultado dos diferentes modelos de desenvolvimento adotados nos países, principalmente no que se refere às instâncias política e econômica, e tem reflexo direto nas condições naturais e na qualidade de vida da população. O espaço geográfico, como objeto de estudo da Geografia, tem na perspectiva ambiental a oportunidade de uma análise crítica da degradação do ambiente, surgindo, assim, uma conjuntura favorável à reflexão e ações dos sujeitos nesta temática, articulando os componentes físicos, sociais e econômicos.

A bacia hidrográfica é reconhecida como unidade espacial na Geografia Física desde o final da década de 1960 e entendida como célula básica de análise ambiental, permitindo "conhecer e avaliar seus diversos componentes e os processos e interações que nela ocorrem" (BOTELHO; SILVA, 2004, p.153). Ainda de acordo com os autores, ao distinguirmos o estado dos elementos que compõem o sistema hidrológico e os processos a eles relacionados, somos capazes de avaliar o equilíbrio do sistema ou ainda a qualidade ambiental nele existente.

A bacia hidrográfica deve ser compreendida considerando os elementos urbanos que dela fazem parte, como por exemplo as indústrias, as comunidades, as ruas asfaltadas e os lixões. Nesse sentido, a bacia hidrográfica também pode ser definida como o "palco unitário de interação das águas com o meio físico, o meio biótico e o meio social, econômico e cultural" (YASSUDA, 1993, p.08).

\section{b. Geomorfologia e Depósitos Tecnogênicos nos estudos ambientais}

A Geomorfologia tem importante contribuição na abordagem de sistemas ambientais face às intervenções antrópicas. No que se refere às bacias hidrográficas, a análise geomorfológica é essencial para se compreender a diversidade topográfica correspondente às diversas subzonas da bacia e os estudos morfométricos, oferecendo vários tipos de indicadores que podem ser usados para avaliar o comportamento hidrológico (CHRISTOFOLETTI, 2012). A bacia hidrográfica é uma unidade integradora dos setores naturais e sociais, reveladora de impactos ambientais que na área de drenagem ocorrem. Conforme Guerra e Cunha:

\begin{abstract}
As bacias hidrográficas contíguas, de qualquer hierarquia, estão interligadas pelos divisores topográficos, formando uma rede onde cada uma delas drena água, material sólido e dissolvido para uma saída comum ou ponto terminal, que pode ser outro rio de hierarquia igual ou superior, lago, reservatório ou oceano (GUERRA e CUNHA, 2010, p.353).
\end{abstract}

Inseridas no contexto hidrológico natural, as atividades humanas podem gerar materiais sólidos ou dissolvidos que, de acordo com o dinamismo geomorfológico, irão refletir nos corpos líquidos superficiais por meio do mecanismo de transporte com posterior deposição. As bacias hidrográficas integram o comportamento 
conjunto das condições naturais e das atividades humanas nelas desenvolvidas e, através de mudanças significativas em qualquer dessas unidades, pode gerar alterações, efeitos ou impactos a jusante e nos fluxos energéticos de saída como descarga, cargas sólidas e dissolvidas (GUERRA e CUNHA, 2010).

Os depósitos tecnogênicos podem ser categorizados como uma classe de formação superficial criada devido à ação geológica da humanidade, conceito original de Chemekov (1983). De acordo com o autor, os depósitos tecnogênicos são resultado da atividade humana, com os processos de transporte e sedimentação independentes do clima e da tectônica, possuindo composição variada e ampla faixa de espessura. Para Chemekov (1983), estes depósitos podem ser classificados de acordo com a gênese, composição e morfologia, sendo subaérea, subaquática e subterrânea.

No Brasil, Oliveira (1990) diferencia os depósitos tecnogênicos em três tipos principais: os depósitos acumulados resultantes da ação humana direta; os depósitos modificados caracterizados por serem naturais, porém transformados por ação humana, e; depósitos induzidos, provenientes de processos naturais modificados, como a erosão acelerada (OLIVEIRA, 1990).

De acordo com Peloggia (1995), a capacidade do homem de modificar a natureza é cada vez mais intensa:

\section{[...] o homem é um agente especificamente geológico na medida em que as consequências de suas atividades (sua ação sobre a natureza, ação ativa e mediatizada pelo trabalho) são comparáveis qualitativamente e quantitativamente significativas em relação a processos naturais e, ainda mais, quando os efeitos produzidos materializam-se em marcos estratigráficos (PELOGGIA, 1995, p.108).}

Conforme Peloggia (1999), as transformações na paisagem e modificação de ambientes por meio das intervenções humanas ocorrem num curto espaço de tempo, denominado tempo histórico, e em escala localizada em detrimento da escala regional. $O$ autor menciona o termo tecnogênico-aluvial quando se refere à composição dos materiais induzidos.

Pode-se distinguir o material constituinte de origem natural provenientes da ação humana a partir dos processos (erosão, transporte e deposição) e, o material constituido de elementos tecnogênicos (fragmentos metálicos, de vidro, de poeira, detritos industriais, de construção etc.), misturados à partículas naturais líticas e relacionados à fonte dos componentes tecnogênicos e a pujanção fluvial (PELOGGIA, 1999). O autor elaborou uma classificação para os depósitos resultantes do trabalho humano como construídos (aterros), induzidos (assoreamento) e modificados (depósitos naturais alterados tecnogenicamente).

Uma base sólida de conhecimento sobre a dinâmica geomorfológica atual é importante nos estudos ambientais. Depósitos superficiais e subsuperficiais em áreas de planícies de inundação podem preservar testemunhos dos processos que ocorrem à montante da bacia hidrográfica, revelando importantes assinaturas das atividades antrópicas desenvolvidas.

Conforme Moura (2012), o primeiro nível de intervenção está na esfera da cobertura vegetal e no uso da terra, através da retirada da cobertura vegetal. $O$ 
segundo nível de intervenção ocorre através da criação de nova morfologia, ligada à mineração e ao meio urbano. Nessa fase são elaborados grandes cortes e/ou aterros no terreno para instalação do sistema viário e posterior instalação das construções. Durante a instalação dessas construções, os materiais superficiais são modificados através de uma nova distribuição, de uma nova estruturação dos depósitos e de uma modificação na resistência dos agregados. A autora reforça essas etapas quando cita Peloggia (1998), no qual este afirma que a ação humana sobre a natureza tem consequências em três níveis: na modificação do relevo, na alteração da dinâmica geomorfológica e na criação de depósitos correlativos comparáveis aos do Quaternário (os depósitos tecnogênicos) devido a um conjunto de ações denominada tecnogênese (MOURA, 2012).

Perante a capacidade do ser humano de intervir nas dinâmicas naturais, capaz de provocar um ritmo acelerado na transformação das paisagens, o "tempo que faz" (SUERTEGARAY, 2017) e a escala local surgem com importância nos estudos ambientais. Os processos morfodinâmicos que atuam sobre a superfície em ritmo acelerado ou, em outras palavras, em um tempo histórico, resultam em recortes espaciais variados em decorrência do fator antrópico. Esse tempo consome e transforma a superfície terrestre em escala primordialmente local, induzindo à modificação de processos naturais através do uso e ocupação da terra.

De acordo com Lambin e Geist (2006), mudanças locais no uso e cobertura da terra são tão significativas que, quando agregados globalmente, podem afetar significativamente aspectos centrais do funcionamento do Sistema Terrestre e funções de suporte à vida e meios de subsistência humanos. De acordo com os autores, é de suma importância compreender as transições de uso da terra e as taxas de expansão nas diferentes localidades controladas por fatores econômicos para identificar a escala espacial dos impactos. (LAMBIN e GEIST, 2006).

\section{Materiais e Métodos}

\subsection{Campo}

O trabalho começou a ser desenvolvido a partir da observação dos pontos de inundação e/ou alagamentos no arroio Sapucaia e em um de seus afluentes, arroio Santa Tecla, após eventos de grande precipitação. Os locais observados possuem topografia plana e acumulam grande carga sedimentar, incluindo descarte (plástico, borracha, vidros etc.) retido pela vegetação.

A identificação textural dos sedimentos obtidos em superfície ocorreu através da coleta de testemunhos em campo e separação em laboratório das amostras obtidas conforme análise textural em classificação de Shepard (1954), escala granulométrica de Wentworth (1922) e sedimentação de silte e argila conforme Lei de Stokes (1851).

Foram escolhidos três pontos de coleta em diferentes cotas altimétricas e identificados, respectivamente, de jusante à montante, como ponto 1 (P1 - 39 metros), ponto 2 (P2 - 50 metros) e ponto 3 (P3 - 79 metros). Um critério importante na escolha dos pontos foi a alta densidade de drenagem, área de nascentes e com a presença de atividade mineradora de rocha ígnea (textura subfanerítica, possivelmente gabro), sendo os dois primeiros locais de coleta situados à jusante da área de extração.

Para0nde!?, Porto Alegre, v.15, n.1, p.96-111, 2021. http://seer.ufrgs.br/paraonde 
A denominação ponto é atribuída ao ambiente identificado no espaço e cartografado, conforme escala compatível, como área deposicional em superfície plana; o testemunho designa a sondagem no terreno com o cano de PVC mais o material capturado no interior; e a amostra corresponde ao material efetivamente coletado e separado em laboratório.

Durante o reconhecimento prévio dos terrenos em campo foi necessário o uso das seguintes ferramentas: uma barra de ferro de $130 \mathrm{~cm}$ de comprimento por $5 \mathrm{~cm}$ de diâmetro e uma marreta de mão de $1 \mathrm{~kg}$. O terreno apresentou pouca resistência à penetração vertical do objeto de ferro, considerando que os testes foram realizados com solo úmido e tempo seco após dois dias seguidos de chuvas. Foram realizadas um total de dez perfurações em cada um dos três pontos escolhidos.

Posteriormente, após duas semanas do reconhecimento prévio, na fase de coleta, foram utilizados os seguintes materiais: caderneta de campo, mapa para a localização dos pontos, pá-de-corte, serrinha manual, trena, sacos plásticos, caneta marcadora permanente de ponta fina $(2 \mathrm{~mm})$, canos de PVC de $50 \mathrm{~mm}$ e $125 \mathrm{~cm}$ de comprimento com lamelas metálicas presas a uma das extremidades, braçadeira de percussão e batente de $50 \mathrm{~mm}$.

Nos três pontos, de jusante à montante, identificados como Ponto 1 (P1), Ponto 2 (P2) e Ponto 3 (P3), foram coletados dois testemunhos com a identificação de Testemunho 1 (T1) e Testemunho 2 (T2), como segue: P1T1, P1T2; P2T1, P2T2; P3T1, P3T2.

\subsection{Laboratório}

A sequência do trabalho foi desenvolvida em laboratório especializado nas dependências do Centro de Estudos de Geologia Costeira e Oceânica/Instituto de Geociências da Universidade Federal do Rio Grande do Sul (CECO/UFRGS). Os testemunhos foram abertos sob supervisão técnica, com realização de descrição visual prévia dos acamamentos e fácies deposicionais, bem evidentes, para após serem encaminhadas para análise granulométrica.

As sequências deposicionais registradas nos testemunhos foram separadas para análise sendo respeitados os limites entre uma fase de deposição e outra demonstradas nas colunas entre topo e base. A cada fase deposicional foi atribuída a nomenclatura Amostra (A) com o topo sempre identificado como primeira amostra (A1).

O primeiro testemunho coletado no ponto 1 (P1T1) foi descartado por apresentar quantidade representativamente insuficiente para análise, uma vez que pouco material foi acumulado em coluna sedimentar com textura uniforme, aparentemente lamosa.

\section{Resultados}

\subsection{Localização e Caracterização da área de Estudo}

A bacia de drenagem do arroio Sapucaia situa-se no leste do Estado do Rio Grande do Sul e abrange os municípios de Cachoeirinha, Canoas, Esteio, Gravataí, Novo Hamburgo e Sapucaia do Sul, na Região Metropolitana de Porto Alegre (RMPA), compondo a bacia do Rio dos Sinos. A figura 1 apresenta a localização da 
área de estudo e destaca os pontos em que foram coletados materiais nos trabalhos de campo.

Figura 1 - Localização da bacia hidrográfica do arroio Sapucaia.

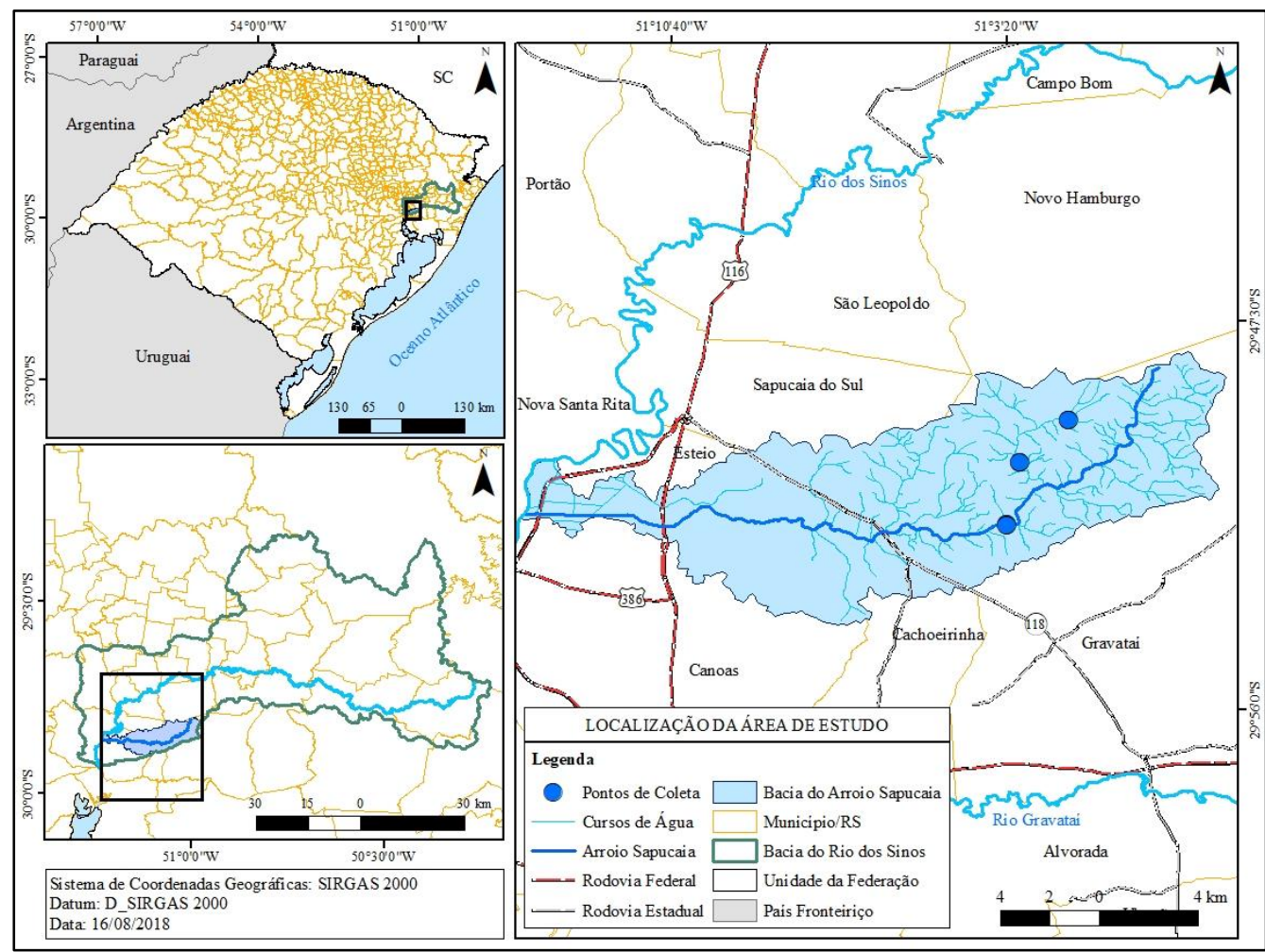

Fonte: Elaboração própria (2018).

A área hidrográfica pesquisada é composta por nascentes de arroios da bacia hidrográfica do Arroio Sapucaia em ambiente rural, porém localizada próxima ao tecido urbano da RMPA, convivendo com a possibilidade da expansão urbana.

A unidade geológica da área de estudo corresponde à porção sudeste da Bacia do Paraná, uma estrutura intracratônica desenvolvida sobre crosta continental que foi sendo preenchida ao longo do tempo geológico por rochas sedimentares e vulcânicas.

A Bacia do Paraná, conforme base cartográfica do Serviço Geológico do Brasil (CPRM, 2008), é estruturada por litologias de idade Fanerozoica (Paleozoico, Mesozoico e Cenozoico), que vão desde o Permiano Superior ao Cretáceo, originadas a partir de ambientes marinhos e continentais, eólicos, glaciais, fluviais, lacustres e deltaicos. A área de estudo compreende três unidades litológicas que compõem a morfoestrutura da Bacia do Paraná, sendo elas as formações Rio do Rasto, Pirambóia e Serra Geral, além dos Depósitos elúvio-coluviais e aluvionares recentes.

A formação Rio do Rasto é datada no Permiano Superior, constituída por arenitos finos avermelhados, intercalados em siltitos e argilitos; a formação Triássica Pirambóia é composta por siltitos e argilitos vermelhos, arenitos de médio a grossos rosados, finos a médios avermelhados quartzosos; a formação Serra Geral tem sua 
composição representada por rochas vulcânicas básicas a intermediárias cinza a cinza-escuras, constituindo derrames de basalto a diques de diabásio relacionados ao magmatismo da Bacia do Paraná nos períodos Jurássico-Cretáceo. Os depósitos de leques aluviais estruturados por depósitos continentais de encostas e leques aluviais constituídos por arenitos e conglomerados fracamente consolidados, areias e argilas de variadas cores entre vermelho, amarelo e cinza, que datam dos Períodos Paleógeno, Neógeno e Quaternário (CPRM, 2006).

As litologias correspondentes à área de estudo são compostas principalmente por arenitos e rochas vulcânicas e formam reservatórios que dão origem a uma densa rede de drenagem como hoje se apresenta, identificadas na figura 2. Por sua vez, as áreas deposicionais de idade recente sustentam a extensão urbana.

\section{Figura 2 - Mapa das formações geológicas na bacia hidrográfica do arroio Sapucaia.}

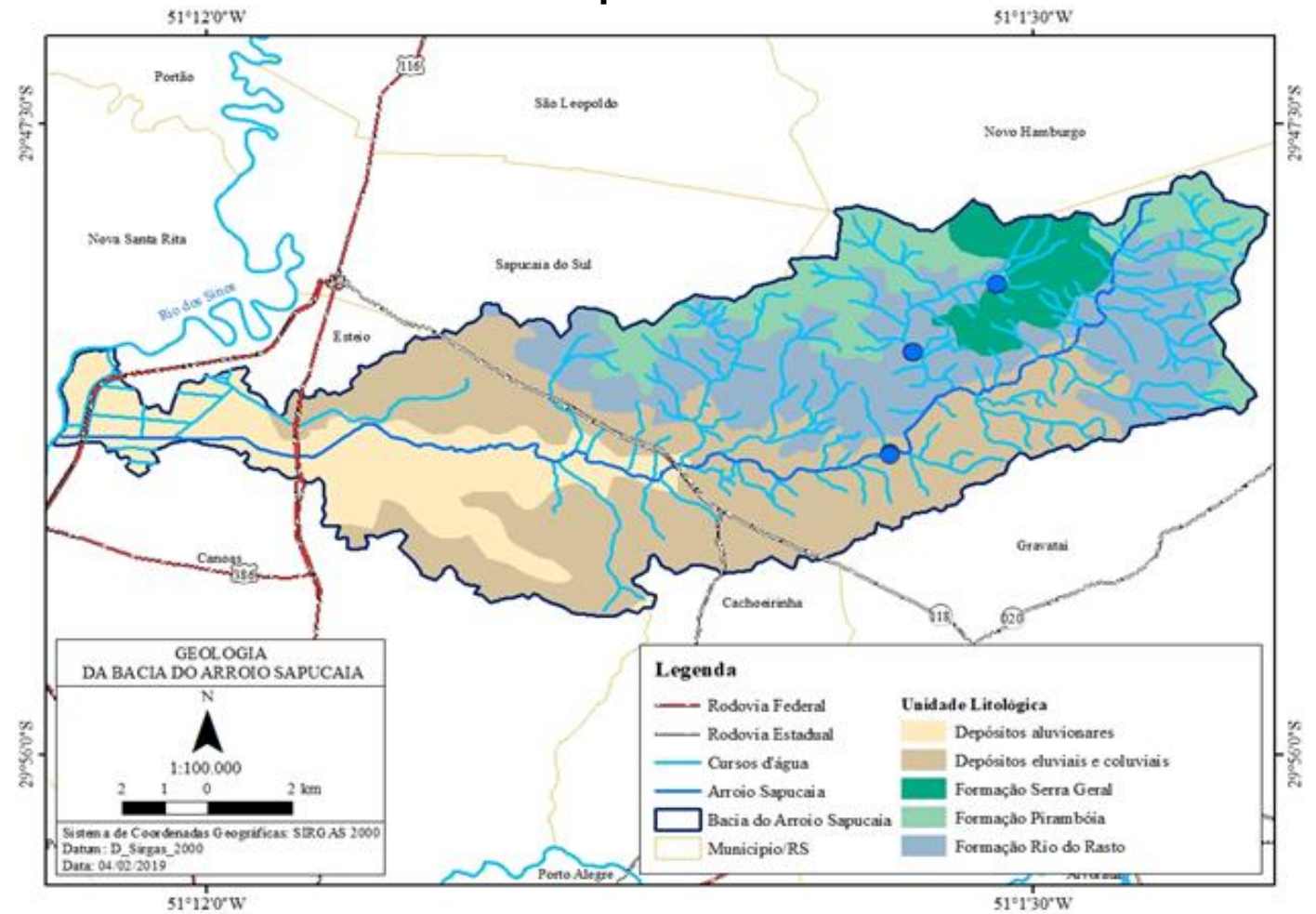

Fonte: Elaboração própria (2019).

A bacia hidrográfica do arroio Sapucaia está situada na região geomorfológica Depressão Periférica do Rio Grande do Sul. A individualização da Depressão Periférica do Rio Grande do Sul é explicada pelo processo erosivo de circunsdenudação, "processo de formação de patamares de erosão, deprimidos e periféricos, que se localizam nas bordas de bacias sedimentares" (AB'SABER, 1949 apud SUERTEGARAY; MOURA, 2012).

A unidade morfológica Depressão Periférica no Rio Grande do Sul é compreendida por Ross (1992) e Suertegaray e Moura (2012) sob o conceito taxonômico de morfoescultura, relacionado às feições do relevo produzidas na Terra pela ação dos climas atuais e pretéritos ao longo do tempo geológico na 
morfoestrutura (SUERTEGARAY; MOURA, 2012).

A área de estudo está situada sob uma região climática de médias latitudes. $\mathrm{O}$ tipo climático corresponde ao subtropical III, úmido com 1700 a 1800 mm acumulados durante 100 a 120 dias de chuvas anuais e com variações longitudinais de temperaturas, com menor interferencia dos sistemas polares e maior dos sistemas tropicais conjugados com os efeitos do relevo de escarpas e vales da borda do Planalto Basáltico (ROSSATO, 2011).

No Rio Grande do Sul, os Argissolos vermelhos e Argissolos vermelhosamarelos foram identificados a partir dos substratos do basalto, do arenito e do granito, solos que apresentam o horizonte $\mathrm{B}$ argiloso e bem drenados, em decorrências das condições climáticas (clima úmido com precipitações bem distribuídas durante o ano (STRECK et al., 2008). Na área de estudo, ocorre a formação de Argissolos e, em áreas de inundação, Planossolos, próximo a confluencia com o rio dos Sinos.

A densa rede de drenagem na área de estudo remobiliza os sedimentos no interior da bacia e os redistribui, contribuindo para a formação de solos com frações arenosas oriundas da intemperização dos arenitos e das frações argilosas originárias principalmente dos basaltos ao longo do tempo geológico. Entretanto, 0 fator antrópico, ligado ao uso da terra, vem contribuindo para a introdução de objetos originários da produção ou indução humana em camadas superficiais do solo, com reflexos mais marcantes sobre os vales fluviais, originando nestes locais indicadores da ação antrópica em depósitos superficiais mesmo em ambientes com predomínio de atividades rurais.

\subsection{Caracterização do Uso e ocupação da terra}

Em uma primeira análise a bacia hidrográfica em estudo apresenta duas situações espacialmente distintas no que se refere ao uso e ocupação da terra atual nos seus 129,7 km²: ocorre um setor urbano-industrial homogeneizado a oeste, próximo à foz com o rio dos Sinos, assentado sobre altitudes de até 30 metros, fraca declividade e corresponde aproximadamente a um terço da área total da bacia hidrográfica; outro setor espacialmente fragmentado a leste com uso predominantemente rural, com vegetação remanescente que soma $41 \%$ da área total entre campos e matas, local que conserva a rede de drenagem original e setores topográficos acima de 200 metros de altitude.

Entretanto, dentre as duas situações espacialmente distintas foram identificadas treze classes representativas do uso da terra na bacia hidrográfica do arroio Sapucaia. O estudo desperta atenção para a degradação que vem ocorrendo na área das nascentes, especialmente na sub-bacia do arroio Santa Tecla, onde foram identificados acelerados processos erosivos nas encostas atravessadas por estradas e assoreamento de canais, banhados e campos. A seguir, na figura 3, pode-se observar o produto cartográfico atualizado de uso e ocupação da terra desenvolvido na pesquisa e as informações quantitativas derivadas do mapeamento, identificadas na tabela 1. 
Figura 3 - Mapa de uso e ocupação da terra na bacia hidrográfica do arroio Sapucaia.

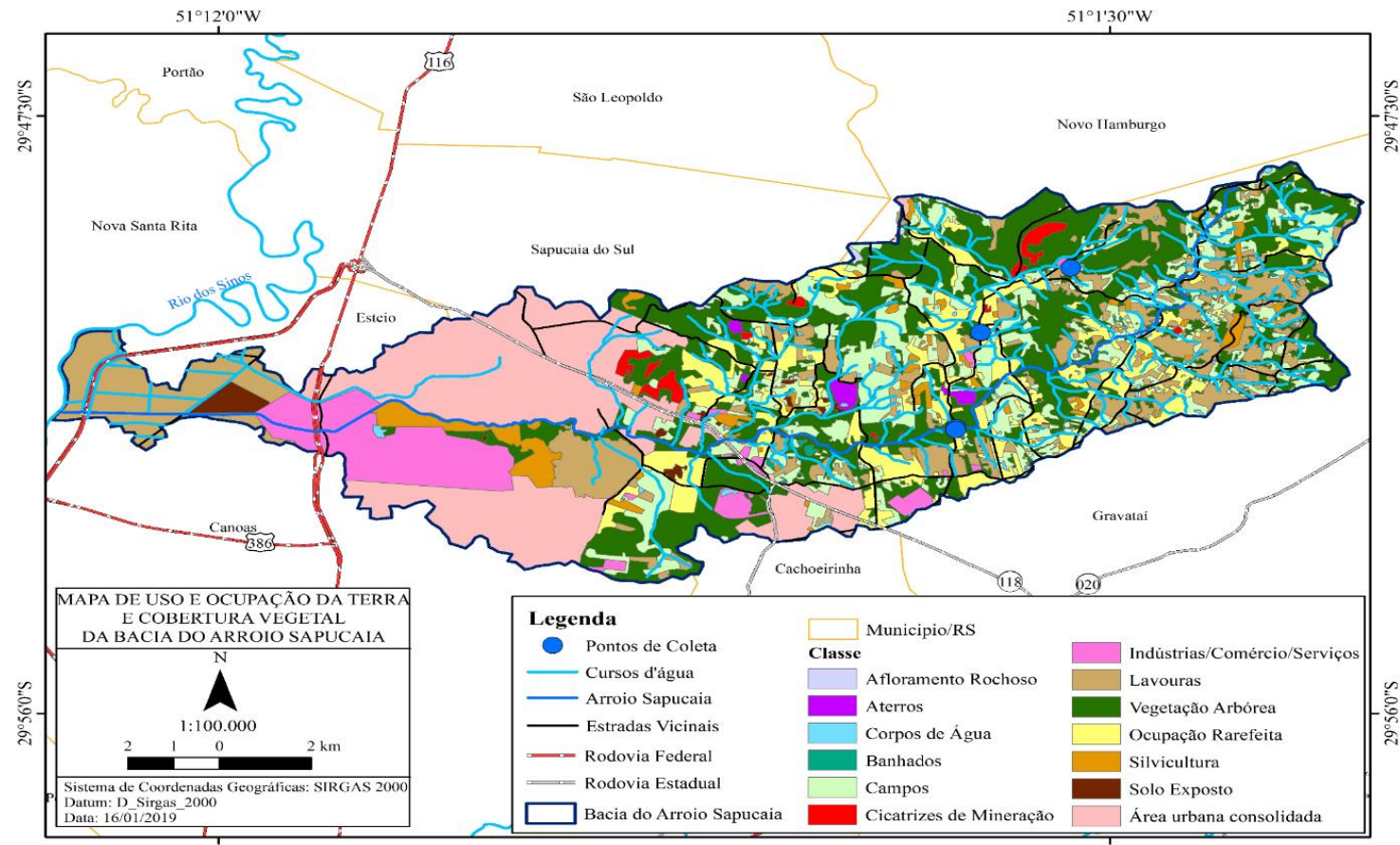

Fonte: Eláb'oräação própria (2019).

Tabela 1 - Dados quantitativos referentes às treze classes de uso e ocupação da terra na bacia hidrográfica do arroio Sapucaia.

\begin{tabular}{llll}
\hline \multicolumn{1}{c}{ Classes } & Área $\left(\mathbf{k m}^{2}\right)$ & $\%$ & $\mathbf{n}^{\circ}$ de Frangmentos \\
\hline Afloramento Rochoso & 0,1 & 0,079937397 & 3 \\
Aterro & 0,5 & 0,434548637 & 4 \\
Banhado & 0,3 & 0,234890006 & 31 \\
Campo & 17,8 & 13,75338032 & 207 \\
Cicatrizes de Mineração & 1,5 & 0,955935022 & 12 \\
Corpo de Água & 0,6 & 0,466529575 & 127 \\
Indústrias/Comércio/Serviços & 8,4 & 6,373351982 & 12 \\
Lavoura & 20,3 & 15,68821253 & 180 \\
Ocupação Rarefeita & 13,7 & 10,6109976 & 95 \\
Silvicultura & 4,2 & 3,255702463 & 74 \\
Solo Exposto & 1,0 & 0,791654555 & 16 \\
Vegetação Arbórea & 37,3 & 28,81297137 & 73 \\
Urbano Consolidado & 24,0 & 18,54188855 & 5 \\
\hline TOTAL & 129,7 & 100 & 839 \\
\hline
\end{tabular}

Fonte: Elaboração própria (2019). 
Com base no estudo foram identificadas treze classes representativas do uso atual da terra na bacia hidrográfica do arroio Sapucaia. O estudo desperta atenção para a degradação que vem ocorrendo na área das nascentes, especialmente na sub-bacia do arroio Santa Tecla, onde foram identificados acelerados processos erosivos nas encostas atravessadas por estradas e assoreamento de canais, banhados e campos. A atuação da extração de rocha ígnea (textura subfanerítica, possivelmente gabro) parece exercer considerável pressão sobre a sub-bacia do arroio Santa Tecla, afluente do arroio Sapucaia, a considerar sua extensão de 16,3 $\mathrm{km}^{2}$ frente à pujança extrativista, principalmente por disponibilizar ao ambiente excesso de materiais derivados da exploração comercial e facilitar, de certo modo, o carreamento destes materiais para o leito dos arroios, principalmente após intensas e volumosas chuvas.

Os processos erosivos e de assoreamentos podem estar sendo potencializado pelo fator antrópico de caráter endógeno, gerado pelos sismos via detonação das dinamites na pedreira, causando desagregação dos materiais nas encostas e rachaduras nas residências próximas. As áreas das nascentes, embora com importante parcela de vegetação arbórea e mata ciliar, mostram evidências da atuação antrópica através de formas erosivas por ação hídrica. Tais processos ocorrem em função da abertura de estradas perpendiculares à linha de drenagem em terrenos de elevadas altitudes e fortes declividades em cursos d'água de primeira ordem.

Os dados quantitativos granulométricos obtidos através de análise dos sedimentos em laboratório estão discriminados na tabela 2.

\section{Tabela 2 - Tabela granulométrica de material coletado em campo e analisados em laboratório.}

\begin{tabular}{|c|c|c|c|c|c|c|c|c|c|}
\hline \multicolumn{10}{|c|}{ DADOS DE GRANULOMETRIA DAS AMOSTRAS (TEXTURAL DE SHEPARD) } \\
\hline Pontos $(\mathrm{P})$, Testemunhos $(\mathrm{T})$ e Amostras $(\mathrm{A})$ & Espessura $(\mathrm{cm})$ & Cascalho $(\%)$ & \multicolumn{5}{|c|}{ Areia (\%) } & Silte (\%) & Argila (\%) \\
\hline Ponto 1 Testemunho 2 (P1T2): & $25 \mathrm{~cm}$ & & Muito Grossa & Grossa & Média & Fina & Muito Fina & & \\
\hline Base (A3)* & 15 a 25 & 23,3 & 2,9 & 4,5 & 6,2 & 13,9 & 18,2 & 25,5 & 5,5 \\
\hline Meio (A2)* & 8 a 14 & 10,9 & 2,1 & 4,3 & 7,8 & 17,6 & 21,1 & 24 & 12,2 \\
\hline Topo (A1) & 0 a 7 & Eliminado & Eliminado & Eliminado & Eliminado & Eliminado & Eliminado & Eliminado & Eliminado \\
\hline Ponto 2 Testemunho 1 (P2T1): & $51 \mathrm{~cm}$ & & & & & & & & \\
\hline Base (A3) & 31 a 51 & 0,2 & 0,2 & 14,2 & 55,9 & 22,3 & 2,3 & 4,9 & 0 \\
\hline Meio (A2) & 11 a 30 & 0,6 & 1,2 & 25,7 & 48,3 & 18,8 & 3 & 2,4 & 0 \\
\hline Topo (A1) & 0 a 10 & 0 & 1,1 & 16,3 & 45,4 & 28 & 4,7 & 4,5 & 0 \\
\hline Ponto 2 Testemunho 2 (P2T2): & $47 \mathrm{~cm}$ & & & & & & & & \\
\hline Base (A4) & 39 a 47 & 0 & 0 & 12,1 & 47 & 29,4 & 7,3 & 4,2 & 0 \\
\hline Base-meio (A3) & 29 a 38 & 0,4 & 0,6 & 23,9 & 38,8 & 21,7 & 6,8 & 7,8 & 0 \\
\hline Topo baixo (A2) & 19 a 28 & 0 & 0,1 & 8,7 & 41,6 & 31,5 & 12,6 & 5,7 & 0 \\
\hline Topo (A1)* & 0 a 18 & 0,1 & 0,2 & 4,9 & 28 & 37,6 & 16,8 & 12,5 & 0 \\
\hline Ponto 3 Testemunho 1 (P3T1): & $30 \mathrm{~cm}$ & & & & & & & & \\
\hline Base (A2) & 10 a 30 & 0 & 0,6 & 3 & 7,7 & 43,3 & 34,5 & 10,7 & 0,2 \\
\hline Topo (A1) & 0 a 9 & Eliminado & Eliminado & Eliminado & Eliminado & Eliminado & Eliminado & Eliminado & Eliminado \\
\hline Ponto 3 Testemunho 2 (P3T2): & $41 \mathrm{~cm}$ & & & & & & & & \\
\hline Base (A3) & 35 a 41 & 0,1 & 0,3 & 1,4 & 11 & 44,9 & 31,7 & 10,9 & 0 \\
\hline Meio (A2) & 23 a 34 & 0,1 & 0,6 & 2,2 & 23,1 & 49,5 & 19,4 & 5,3 & 0 \\
\hline Topo (A1) & 0 a 22 & Eliminado & Eliminado & Eliminado & Eliminado & Eliminado & Eliminado & Eliminado & Eliminado \\
\hline
\end{tabular}

Fonte: Elaboração própria (2019). 
Algumas amostras acusaram a ocorrência de material tecnogênico, objetos exumados após ensaios na etapa de laboratório, como demonstrado na figura 4.

\section{Figura 4 - Materiais tecnogênicos encontrados durante etapa de análise em laboratório após secagem em estufa.}

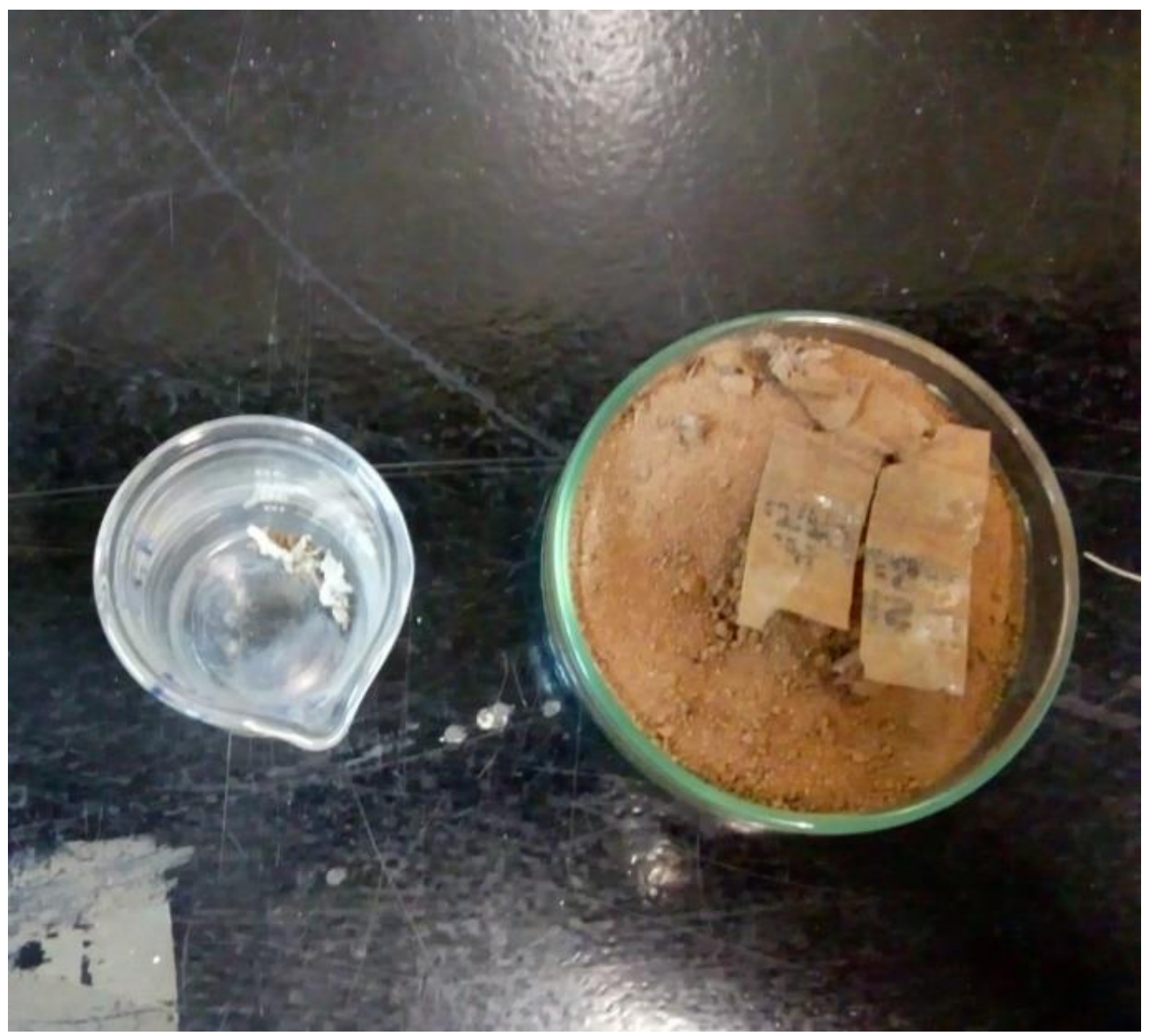

Fonte: Elaboração própria (2018).

A separação dos materiais contidos nos testemunhos entre os tamanhos argila, silte, areias e cascalho (conforme classes de Shepard e Escala de Wentworth) e a análise das amostras obtidas indicaram a ocorrência de materiais tecnogênicos superficiais. A granulometria dos materiais identificados nas amostras então identificadas na tabela 2.

A parcela representativa de cascalhos principalmente nos pontos à jusante da área de exploração mineral indicou material de coloração cinza escuro e grãos angulosos, entre outros arredondados, que indicam origem na mineração à montante da área de estudo, evidenciando que as atividades econômicas induzem a redistribuição de material de origem natural sobre a área hidrográfica. As amostras obtidas no ponto de coleta em questão são demonstradas na figura 5. 


\section{Figura 5 - Fragmentos rochosos coletado do testemunho entre 14 a $25 \mathrm{~cm}$ de profundidade em P1A2.}

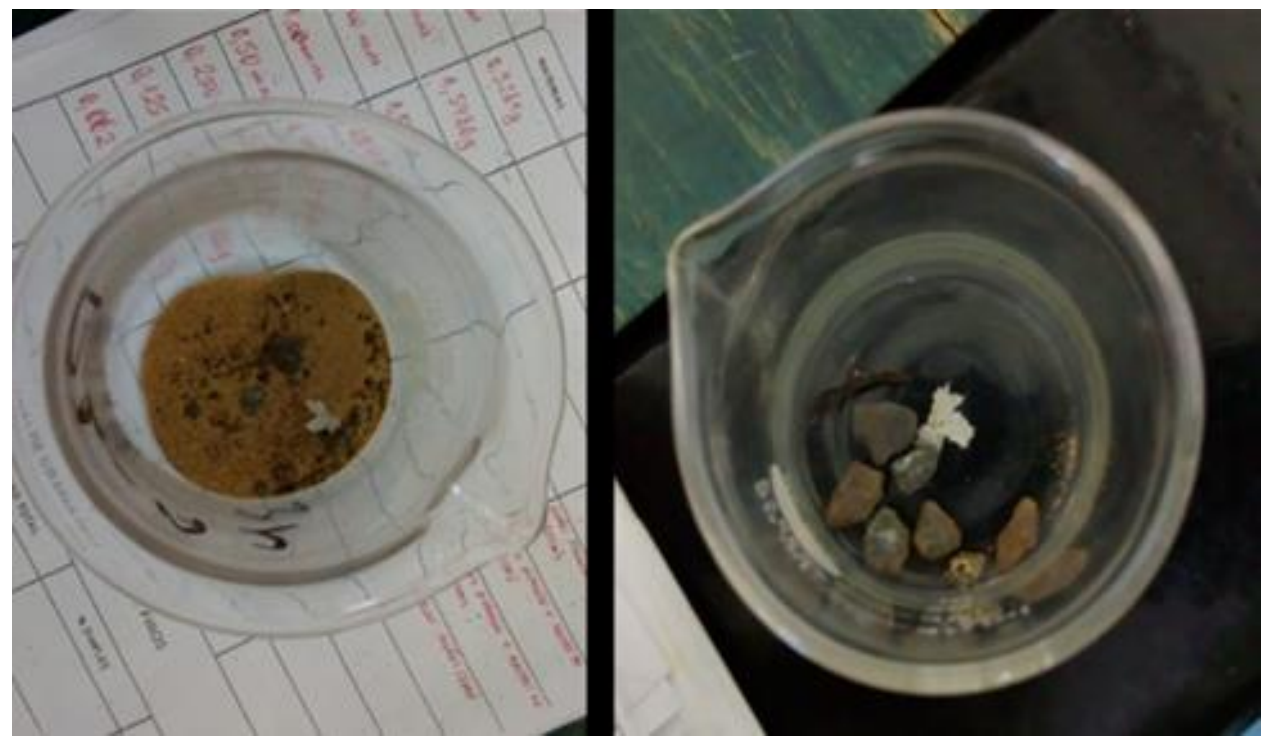

Fonte: Elaboração própria (2018).

A figura 5 indica lascas rochosas com diâmetro relativo em tamanho cascalho médio $(4 \mathrm{~mm})$ conforme Escala de Wentworth. Observa-se, também, frações de origem antrópica.

As observações em trabalhos de campo, a coleta de materiais e o mapeamento de uso e ocupação da terra demonstraram que o ambiente na área de estudo convive com acelerado processo de degradação com importante contribuição da atividade mineradora de gabro. Tal empreendimento econômico promove redistribuição dos sedimentos; compromete o equilíbrio dos cursos d'água, em especial nas nascentes do arroio Sapucaia e; contamina a área de recarga de aquífero, pois encontra-se na borda da da bacia sedimentar do Paraná, composta de rochas areníticas.

\section{Considerações Finais}

Os testemunhos sedimentares permitiram identificar indícios de atividades influenciadas pelo uso do solo em amostragem textural e o mapeamento contribuiu para a espacialização dos possíveis eventos relacionados. Os estudos partiram do entendimento de que as alterações provocadas pelo uso da terra têm reflexos na dinâmica fluvial por meio da geração de materiais oriundos principalmente da mineração.

As atividades humanas na área da bacia hidrográfica do arroio Sapucaia, situada na quarta Região Metropolitana mais populosa do Brasil, conforme IBGE (2010), Região Metropolitana de Porto Alegre, contribuem para gerar profundas alterações antrópicas que são materializadas na paisagem, o que ocasionou mudanças geomorfológicas (formas, processos e materiais), observadas, principalmente, na construção de aterros e remobilização de material lítico através 
da mineração de rochas ígneas, constatados no estudo. As atividades ligadas às intervenções, principalmente através da mineração, tornam-se objeto de preocupação porque ocorrem próximas às áreas de recarga e cabeceiras de drenagem.

A realização de estudos em laboratório do material testemunho foi fundamental para a compreensão dos processos atuantes nos pontos de coleta e nas partes à montante destes na bacia hidrográfica do arroio Sapucaia, atingindo o objetivo proposto pelo estudo. Identificou-se, através dos materiais encontrados, a influência da mineração no que se refere à oferta ao sistema de sedimentos oriundos da extração, bem como objetos de fabricação humana como lascas de tecidos e fragmentos de embalagem plástica, demonstrando o fator antrópico no espaço das nascentes na área de estudo.

A produção de mapeamento de uso e ocupação da terra demonstrou que a bacia hidrográfica do arroio Sapucaia possui características de densa urbanização da mancha metropolitana e indícios de degradação ambiental próximo às nascentes em meio rural mais afastado, ainda que a ocupação não seja intensa nesta área e predomine classe de vegetação arbórea e campos.

Embora a ocupação urbana densa encontre-se longe das nascentes, evidenciada pela classe de uso denominada Ocupação Rarefeita, as alterações ambientais geradas através da atividade mineradora e construção de estradas, resultaram em processos de erosão laminar, facilitando o carreamento de detritos, por ocasião dos eventos chuvosos, para os cursos d'água e banhados.

\section{Referências}

BOTELHO, R.G.M.; SILVA, A.S. Bacia Hidrográfica e Qualidade Ambiental. In: GUERRA, A.J.T e VITTE, A.C. (org). Reflexões sobre a Geografia Física no Brasil. Rio de Janeiro: Bertrand Brasil, 2004, 280p.

CHEMEKOV, Y.F. Tecnogenic deposits. In: INQUA Congress, 11, Moscow, Abstracts...v.3, p.62, 1983.

CHRISTOFOLETTI, A. Geomorfologia. São Paulo, Editora Edgard Blucher, 2 ${ }^{a}$ ed. 1980.

CHRISTOFOLETTI, A. Aplicabilidade do Conhecimento Geomorfológico nos Projetos de Planejamento. In: Guerra, A.J.T e Cunha, S.B. (org). Geomorfologia, Uma Atualização de Bases e Conceitos. $11^{a}$ ed. Rio de Janeiro: Bertrand Brasil, 2012, 474p.

CPRM. Serviço Geológico Brasileiro, Geologia e recursos minerais do Estado do Rio Grande do Sul. In: Programa geologia do Brasil. Mapas estaduais 1:750.000-SIG. Formato em DVD. 2008.

CPRM - SERVIÇO GEOLÓGICO DO BRASIL. Projeto Plano Diretor de Mineração da Região Metropolitana de Porto Alegre - PDM, 2006. Disponível em: https://sosgisbr.files.wordpress.com/2011/09/mapageologico_poa.jpg. Acesso em: 11 mar. 2018.

GUERRA, A.J.T; CUNHA, S.B. Geomorfologia e Meio Ambiente. Rio de Janeiro: Bertrand Brasil, 2010. 
INSTITUTO BRASILEIRO DE GEOGRAFIA E ESTATÍSTICA - IBGE. Censos Demográficos 1991/2000/2010. Disponível em: http://www.ibge.gov.br. Acesso em: 20 maio 2019.

LAMBIN, E.F.; GEIST, H. Land-Use and Land-Cover Change. Local Processes and Global Impacts: Springer-Verlag Berlin Heidelberg, 2006.

MOURA, J. R. da S. de. Geomorfologia do Quaternário. In: Guerra, A. J. T; Cunha, S.B. (org). Geomorfologia, Uma Atualização de Bases e Conceitos. 11aㅡ ed. Rio de Janeiro: Bertrand Brasil, 2012, 474p.

OLIVEIRA, A.M.S. Depósitos tecnogênicos associados à erosão atual. In: Congresso Brasileiro de Geologia de Engenharia, Salvador. Anais, ABGE: ABMS, v.1, p.411415, 1990.

PELOGGIA, A.U.G. A dialética da Geologia (temas de Geologia inspirados na obra de Friedrich Engels, e suas aplicações). Revista Brasileira de Geociências, São Paulo, v. 25, n.2, p.107:110, 1995.

PELOGGIA, A.U.G. O Homem e o Ambiente Geológico: Geologia, Sociedade e Ocupação Urbana no Município de São Paulo. São Paulo: Xamã, 1998.

PELOGGIA, A.U.G. Estudos de Geotécnica e Geologia Urbana (I). Manual Técnico 3/GT-GEOTC. São Paulo, 1999.

ROSS, J.L.S. O Registro Cartográfico dos Fatos Geomórficos e a Questão da Taxonomia do Relevo. Revista do Departamento de Geografia/FFLCH/USP, n.o 6, 17-29, 1992.

ROSSATO, M.S. Os Climas do Rio Grande do Sul: Variabilidade, Tendências e Tipologia. Tese de Doutorado. Instituto de Geociências. Universidade Federal do Rio Grande do Sul. 2011.

STRECK, E. et al. Solos do Rio Grande do Sul. 2.ed. Porto Alegre: EMATER/RS, 2008, 222 p.

SHEPARD, L.R. 1954. Nomenclature base on sand-silt-clay ratios. Journal of Sedimentary Petrology, 24(3): 151-158.

SUERTEGARAY, D.M.A; MOURA, N.S.V. Morfogênese do Relevo do Estado do Rio Grande do Sul. In: Rio Grande do Sul: Paisagens e territórios em transformação. VERDUM, R; BASSO, L.A; SUERTEGARAY, D.M.A. (org.). 2. Edição. Porto Alegre: Editora da UFRGS, 2012, 360p.

SUERTEGARAY, D.M.A. Religar a Geografia. Natureza e Sociedade. Porto Alegre: Compasso Lugar-Cultura, 2017, 180p.

WENTWORTH, C.K. 1922. A scale of grade and class terms for clastic sediments. Journal of Sedimentary Petrology, 30:377-392.

YASSUDA, E. R. Gestão de recursos hídricos: fundamentos e aspectos institucionais. Rev. Adm. Púb.; v.27, n.2, p.5-18, 1993. 